\title{
von Willebrand Factor: More Than a Regulator of Hemostasis and Thrombosis
}

\author{
Gui-Ping Luo Bing Ni Xia Yang Yu-Zhang Wu \\ Institute of Immunology, PLA, Third Military Medical University, Chongqing, PR China
}

\section{Key Words}

ADAMTS13 $\cdot$ Angiogenesis $\cdot$ Tumors $\cdot$ von Willebrand factor

\begin{abstract}
von Willebrand factor (vWF) was first identified as an adhesive glycoprotein involved in hemostasis by Zimmermann in 1971. Since then, vWF has been shown to play a vital role in platelet adhesion, platelet binding to collagen and factor VIII protection. Recent studies have implicated vWF as a regulator of angiogenesis, smooth muscle cell proliferation, tumor cell metastasis and crosstalk in the immune system. In this review, we will discuss the aspects of vWF structure that facilitate its biological effects and speculate on its newly discovered and hypothesized roles in the pathogenesis of several diseases.

Copyright $\odot 2012$ S. Karger AG, Base
\end{abstract}

\section{Introduction}

The von Willebrand factor (vWF) has two major wellestablished biological functions: mediating adhesion and aggregation of platelets, and acting as a consort for the essential blood clotting factor: factor VIII [1]. Very recently, research studies have provided evidence to indicate that vWF not only regulates hemostasis and thrombosis, but also the processes of angiogenesis, smooth

\section{KARGER}

Fax +41613061234 E-Mail karger@karger.ch www.karger.com
(C) 2012 S. Karger AG, Basel 0001-5792/12/1283-0158\$38.00/0

Accessible online at: www.karger.com/aha muscle cell proliferation and tumor cells metastasis. Interestingly, vWF has also been implicated in proper functioning of the immune system $[2,3]$. Both the size and conformation of vWF can be modified by genetic, physiological and environmental factors, including its cleavage protease ADAMTS13, the adhesive glycoprotein thrombospondin-1 (TSP-1) and shear stress forces.

vWF was first recognized for its role in the hereditary bleeding disorder known as von Willebrand disease (vWD). Since then, vWF has been associated with the thrombotic thrombocytopenic purpura (TTP) clotting disorder, various vascular disorders, liver diseases and cancers, and has emerged as a useful biomarker of these afflictions. It has been theorized that $\mathrm{vWF}$ is in fact a vital endothelial damage indicator and may be a promising diagnostic or prognostic marker of many other diseases. The purpose of this review is to discuss and summarize some of the newly identified and theorized roles of vWF.

\section{The General Aspects of vWF}

vWF is produced exclusively by endothelial cells and megakaryocytes, and is synthesized in the precursor prepro-vWF form. The precursor is composed of four types of domains that are constructed as repeats in the following order: D1-D2-D'-D3-A1-A2-A3-D4-B1-B2-B3-C1C2-CK [4]. The D1 and D2 domains comprise the pro- 


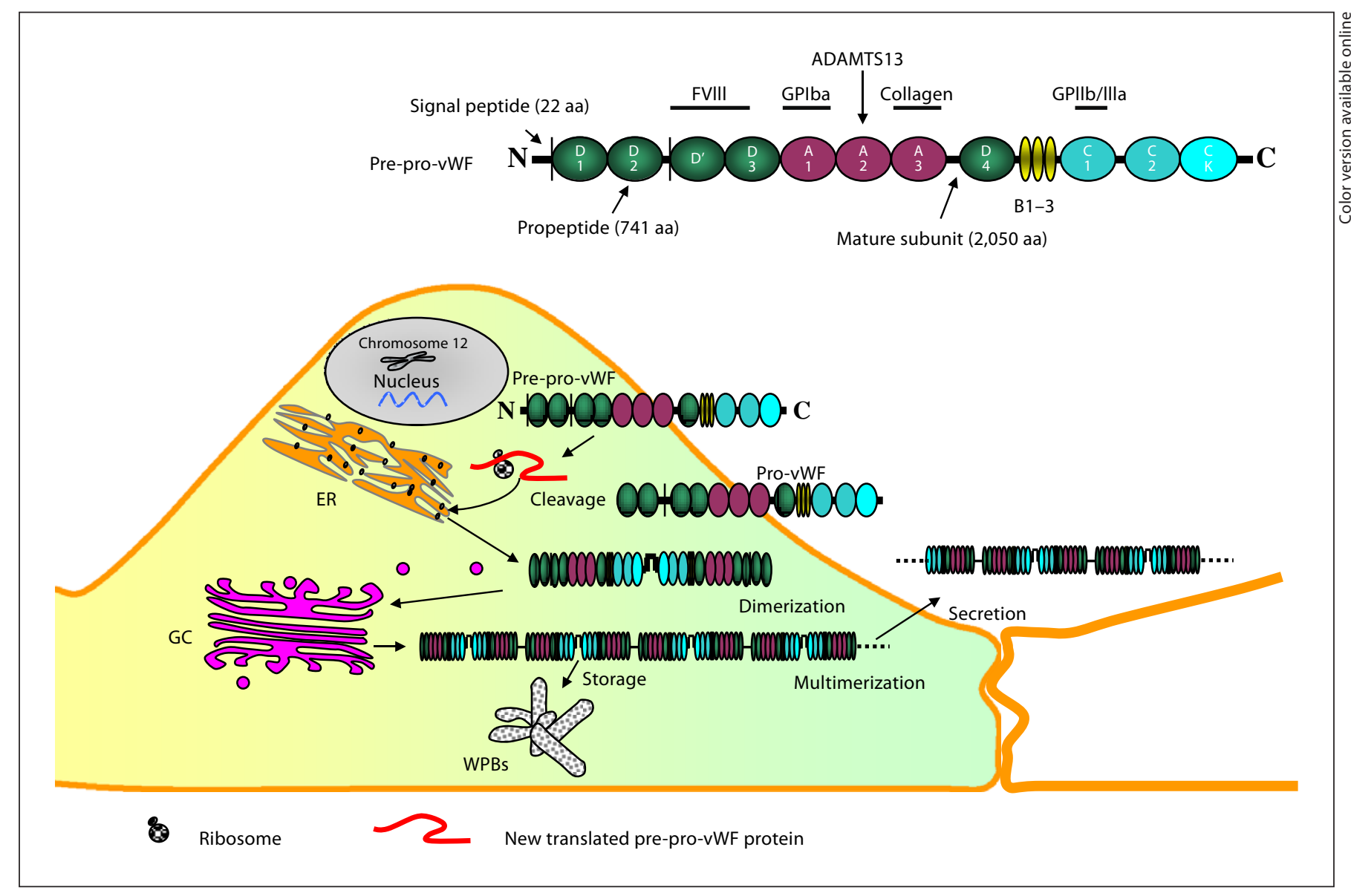

Fig. 1. Overview of vWF synthesis, processing and storage in endothelial cells. The pre-pro-vWF polypeptide is composed of a signal peptide, a propeptide and the mature vWF. The binding sites for different ligands are indicated by arrows. Following synthesis, the signal peptide is cleaved and vWF undergoes dimeriza- tion in the endoplasmic reticulum (ER) and further multimerization in the Golgi complex (GC). The mature vWF is usually stored in Weibel-Palade bodies (WPBs) until the cell is stimulated by a secretagogue. peptide and are cleaved during proteolytic processing to generate the mature vWF. The remaining domains in the mature vWF each carry out specific functions (fig. 1).

The pre-pro-vWF is comprised of 2,813 amino acids (a) which encompass a 22-aa signal peptide, a 741-aa large propeptide and 2,050 aa making up the mature subunit [5]. Proteolytic processing involves cleavage of the signal peptide, which facilitates translocation of vWF into the endoplasmic reticulum. In the endoplasmic reticulum, pro-vWF subunits homodimerize in a 'tail-totail' manner through disulfide bonds that form between the C-terminal residues. The vWF dimers are subsequently transported to the Golgi complex, where further modifications take place, such as the proteolytic removal of the large vWF peptide [6], sulfation of N-linked oligo- saccharides and O-linked glycosylation [7]. While traveling through the Golgi complex, vWF dimers multimerize through self-association of propeptides on adjacent dimers. Further multimerization and propeptide cleavage occur simultaneously in the post-Golgi compartment. vWF produced by endothelial cells is either secreted constitutively or stored in Weibel-Palade bodies, while vWF produced by megakaryocytes is stored in $\alpha$-granules that are later partitioned into platelets (fig. 1).

In response to pathological stimuli, such as inflammation, the circulatory concentration of vWF increases rapidly. Secretion of stored vWF from endothelial cells occurs through both a constitutive and a regulated pathway [8]. Megakaryocytes, however, lack the regulatory pathway, and once they are stimulated, vWF is constitutively 
Table 1. vWF secretion pathways induced by agonists or inhibitors

\begin{tabular}{|c|c|c|}
\hline Secretagogue & Mediator & Receptor \\
\hline VEGF & $\mathrm{Ca}^{2+}$ & VEGFR2 \\
\hline NAADP & $\mathrm{Ca}^{2+}$ & $\mathrm{H} 1 \mathrm{R}$ \\
\hline Histamine & $\mathrm{Ca}^{2+}$ & $\mathrm{H} 1 \mathrm{R}$ \\
\hline Thrombin & $\mathrm{Ca}^{2+}$ & Thrombin receptor \\
\hline Estrogen & $\mathrm{Ca}^{2+}$ & Estrogen receptor \\
\hline \multicolumn{3}{|l|}{ LTs, ROIs, calcium ionophore } \\
\hline $\begin{array}{l}\text { A23187/ionomycin, PMA, C5a } \\
\text { and C5b-9, superoxide anions }\end{array}$ & $\mathrm{Ca}^{2+}$ & UNK \\
\hline Purine nucleotides & $\mathrm{Ca}^{2+} / \mathrm{camp}$ & $\mathrm{P} 2 \mathrm{yR} / \mathrm{A} 2 \mathrm{R}$ \\
\hline Vasopressin (DDAVP) & cAMP & $\mathrm{V} 2 \mathrm{R}$ \\
\hline Epinephrine & cAMP & $\beta 2-A R$ \\
\hline 5-HT, adenosine, prostacyclin & cAMP & UNK \\
\hline Dopamine & Not $\mathrm{Ca}^{2+}$ or cAMP & $\mathrm{D} 2, \mathrm{D} 3, \mathrm{D} 4$ \\
\hline $\mathrm{NO}$ & GCy, cGMP, NSF, $\mathrm{Ca}^{2+}$ & UNK \\
\hline $\mathrm{H}_{2} \mathrm{O}_{2}$ & $\mathrm{Ca}^{2+}$ & UNK \\
\hline
\end{tabular}

cAMP = Cyclic adenosine monophosphate; $\mathrm{cGMP}=$ cyclic guanosine monophosphate; GCy = guanylate cyclase; $\mathrm{UNK}=$ unknown; $\mathrm{A} 2 \mathrm{R}=$ adenosine $\mathrm{A} 2$ receptor; $\beta 2-\mathrm{AR}=\beta 2$-adrenergic receptor; $\mathrm{H} 1 \mathrm{R}=$ histamine $\mathrm{H} 1$ receptor; $\mathrm{P} 2 \mathrm{yR}=\mathrm{P} 2 \mathrm{y}$ purinergic receptor; $\mathrm{V} 2 \mathrm{R}=$ vasopressin 2 receptor.

secreted. Myriad secretagogues and inhibitors can mediate the secretion effects on both vWF-producing cell types. The secretagogues can be divided into two distinct groups: $\mathrm{Ca}^{2+}$-raising agonists and cAMP-raising agonists. There also are three well-studied inhibitors of vWF secretion, namely nitric oxide (NO), hydrogen peroxide $\left(\mathrm{H}_{2} \mathrm{O}_{2}\right)$, and dopamine $[9,10]$ (table 1). vWF is secreted into plasma in an ultra large form (ULvWF) that consists of several hundred vWF monomers. After secretion, the ULvWF travels in the blood flow until it is broken up by sheer stress forces or collisions and molecular interactions with the vessel wall. In a mouse model, circulating vWF was predominantly taken up by the liver (approx. $40-60 \%)$, with the remaining being absorbed by the spleen and kidney [11]. van Schooten et al. [12] demonstrated that macrophages and factor VIII, mainly in the liver, mediate the removal of $\mathrm{vWF}$ from circulating blood. However, the precise cellular membrane receptors for vWF remain unknown.

\section{Determination of vWF Size and Conformation}

The biological function of vWF depends largely on the size of its multimers [13]. Larger multimers are more likely to bind to platelets and collagen, and to promote platelet adhesion in circulating blood. Thus, the ULvWF mul- timers are more active than the largest plasma vWF in inducing platelet aggregation [14]. Since many proteolytic proteins target the available ULvWF to promote clotting, it is essential to maintain a fine balance between ULvWF and proteolysis to generate the smaller vWF forms that function in other processes. Therefore, it is very important for researchers to gain a detailed understanding of the mechanisms regulating vWF size and conformation.

\section{Cleavage by ADAMTS13}

The vWF-cleaving protease ADAMTS13 (a disintegrin-like and metalloprotease with thrombospondin type 1-motif 13) has been purified from both human plasma and factor VIII/vWF concentrates [15]. ADAMTS13 targets the A2 domain of vWF and specifically cleaves the protein between Tyr1605-Met1606 (fig. 1), thereby reducing the ULvWF and hyperactive vWF multimers to smaller and less active forms which can be more readily unfolded by shear forces in flowing blood.

Studies using DNA molecule recombinant technology have demonstrated that two subsites, D187-R193 and D252-P256, can contribute to the cleavage efficiency and site specificity of ADAMTS13 [16]. Furthermore, Zanardelli et al. [17] identified a binding site for ADAMTS13 in vWF residues 1874-2813, and determined that removal of this fragment can inhibit vWF proteolysis. Still an- 
other study determined that a vicinal disulfide bond between C1669 and C1670 in the vWF A2 domain inhibits A2 domain proteolytic cleavage [18]. Four leukocyte proteases have been described that can mediate ADAMTS13targeted A2 domain cleavage. While each of the four have been shown to efficiently process the synthetic vWF substrate FRETS-vWF73, as well as multimeric vWF under denaturing conditions and fluid shear stress [19], the precise cleavage sites and underlying mechanism remain to be elucidated. ADAMTS13 mutants deficient in the Cterminal TSP-1 and CUB domains were found to exist in a hyperactive state under flow conditions, indicating that this C-terminal region might act to negatively regulate ADAMTS13 activity [20].

\section{Disulfide-Bond Reduction by TSP-1}

TSP-1 is a trimeric glycoprotein that acts to further reduce the size of vWF multimers after ADAMTS13 processing. Each TSP-1 subunit is composed of N- and C-terminal globular domains connected by a thin strand. Like vWF, TSP-1 is released from endothelial cells and megakaryocytes and tethers to sites of vascular damage. TSP-1 can then alter multimer size of proximal vWF molecules by splitting the disulfide-bonds that link vWF monomers at its $\mathrm{N}$ - and/or C-terminal ends; in addition, TSP-1 can compete with ADAMTS13 for the same vWF binding site in A2 and A3 domains [21]. Pimanda et al. [22] reported that the vWF-reducing activity of TSP-1 lies in a free thiol located at Cys974 in its C-terminal sequence. Paradoxically, TSP-1 has been shown to protect vWF from degradation by ADAMTS13, both in in vitro and in vivo [23]. Moreover, TSP1-null mice have normal platelet aggregation but impaired $\mathrm{Ca}^{2+}$ ionophore A23187-stimulated endothelial platelet recruitment and reduced thrombus adherence. This phenotype was rescued by injection of human TSP-1 or neutralizing anti-ADAMTS13 antibodies.

\section{Influence of Fluid Shear Stress}

A shear stress is defined as the force that is applied parallel or tangential to the face of a material or molecule, as opposed to normal stress, which is applied perpendicularly. Siedlecki et al. [24] studied the effects of shear stress on vWF structure by atomic force microscopy, and found that $35 \pm 3.5 \mathrm{dyn} / \mathrm{cm}^{2}$ of shear stress caused the molecule to change from a globular to a short extended form, and finally to an extended chain conformation. Thus, the function of shear stress on vWF would be expected to correlate with its velocity. Indeed, fluid shear rates above $2,300-6,000 / \mathrm{s}$ have been shown to promote the aggregation or self-association of purified vWF [25].
Higher shear stresses not only modulate the large form vWF, but can also unfold the ADAMTS13 cleavage site in the A2 domain. In addition, shear stress has been shown to facilitate ADAMTS13 proteolysis of ULvWF multimers [26], probably by exposing the peptide bond in the A2 domain during the overall conformational change in vWF. Zhang et al. [27] used a technique based on optical tweezers to show how ADAMTS13 cleaves vWF under flow. They demonstrated that every single A2 domain that is present in a vWF molecule requires a force of approximately $11 \mathrm{pN}$ to unfold, and that the A2 domain is not cleaved if the mechanical force is below this unfolding threshold.

\section{The Biological Effects of vWF}

There are three types of vWFs in the human body: soluble plasma vWF, basement membrane vWF (extracellular matrix vWF) and cellular vWF. Only the larger multimers of vWF are effective in the control of hemostasis. vWF has three main recognized hemostatic functions, which are to mediate interactions of platelet to platelet and platelet to collagen in the vessel wall, and to serve as a carrier of factor VIII in the circulation system. Recent research has suggested that vWF may have other nonhemostatic functions, including in angiogenesis, smooth muscle cell proliferation, tumor cell metastasis and immune cell regulation.

\section{$v W F$ and Platelet Adhesion}

Under physiological conditions, circulating platelets are recruited from the blood flow to injury sites, where they act to prevent excessive bleeding [28]. vWF is essential in this process, as was demonstrated by platelet agglutination abnormalities in VWD patients who are deficient in vWF. vWD sufferers have a prolonged bleeding time due to impaired platelet plug formation, and transfusion of vWF concentrates can resolve this disorder.

When a vessel membrane is injured, the plasma vWF interacts with circulating platelets through two membrane receptors: known as glycoprotein Ib (GPIb) and the glycoprotein IIb-IIIa (GPIIb-IIIa) complex [29]. GPIb participates mainly in platelet-vessel wall adhesion, while the GPIIb-IIIa complex is involved in both platelet-vessel wall adhesion and crosstalk between platelets. vWF is the only ligand that promotes platelet adhesion by attaching to both of these receptors. However, shear-induced interaction of platelets in the presence of vWF could lead to GpIb $\alpha$ shedding, which can be inhibited through calpain 
cleavage [30]. Mody et al. [31] suggested that the formation of reversible tether bonds between GPIb $\alpha$ and the vWF A1 domain might be formed by hydrodynamic shear flow. Apart from platelet GPIb, Huang et al. [32] discovered that integrin $\alpha \mathrm{v} \beta 3$ can anchor to vWF strings, as observed by immunofluorescence microscopy of living human umbilical vein endothelial cells (HUVECs).

\section{Interactions between $v W F$ and the Subendothelial} Matrix

Endothelium injury exposes the vascular subendothelial matrix to vessel contents. When the subendothelial matrix proteins at the injury site come across the coagulation factors, thrombus formation is initiated. However, this process has to withstand the surrounding high blood flow rates, which can trigger endothelial vWF secretion as the body attempts to ensure that sufficient vWF is available for interactions between platelets [33]. On the other hand, the high shear stress allows conformational changes within vWF, which can result in the exposure of binding sites for platelets or collagen. vWF plays an important role in initiating platelet adhesion onto the extracellular matrix, mainly the collagens. There are two mechanisms that mediate this type of adhesion: a direct mechanism, by which fibrin binds to the GPIIb-IIIa complex directly and an indirect mechanism, by which vWF serves as a bridging agent between fibrin and platelet GPIb.

In static conditions, recombinant soluble vWF with the A3 domain deleted has poor binding ability to collagen fibrils, as compared with a vWF with A1 deleted and intact vWF [34]. The A1 domain of vWF interacts mainly with collagen type VI [35], but can also bind, with less affinity, to collagen types I and III. A3 can also bind to collagens, namely collagen types I and III [36].

Under flow conditions, Bonnefoy et al. [34] found that the A1 domain initiates platelet recruitment to collagen fibers by comparing the binding abilities of intact $\mathrm{vWF}$, an A1-deleted vWF and an A3-deleted vWF. They were also able to confirm that the collagen-vWF antagonist, H1786A-vWF, binds to collagen only through A1, and not A3.

\section{A Carrier of Factor VIII}

Unlike endothelial cell- or megakaryocyte-originated vWF, factor VIII is produced by liver cells as a single chain polypeptide consisting of 2,351 aa. Factor VIII is a cofactor of the intrinsic clotting cascade, and its deficiency manifests as hemophilia A. vWF is the consort for factor VIII [3], effectively extending the half-life of factor
VIII. This phenomenon may be mediated by any of the following mechanisms: (1) structural stabilization of factor VIII; (2) inhibition of phospholipid-binding proteins that target factor VIII for proteolytic degradation; (3) inhibition of factor VIII binding to activated factor IX to stimulate the coagulation pathway, and (4) prevention of factor VIII cellular uptake via scavenger cell receptors $[3$, $12,37]$.

\section{Regulation of Angiogenesis}

Recent research has revealed that vWF has several previously unrecognized biological functions. A regulatory role for endothelial vWF in angiogenesis has been hypothesized based on the fact that VWF is closely related to other well-known regulators of angiogenesis and angiodysplasia in vWD patients $[38,39]$. To test this hypothesis, Starke et al. [40] used short interfering RNA (siRNA) to inhibit vWF expression in HUVECs, and observed stimulated results in angiogenesis, and improved vascular endothelial growth factor (VEGF) receptor-2 (VEGFR-2)-dependent proliferation and migration. VEGFR2 is an important receptor for the key angiogenesis-mediator hormone VEGF-A. That same study also found that vWF-deficient mice had increased angiogenesis and a larger vascular network [41]. Another study used endothelial cells isolated from vWD patients with low levels of plasma activity and antigen to show that the vWD phenotype could be recapitulated. Similarly, blood outgrowth endothelial cell colonies from vWD patients were also observed to have significantly increased tube formation, VEGF-dependent proliferation and basal migration [40]. Collectively, the findings from these studies indicate that endothelial vWF deficiency can promote angiogenesis.

\section{$v W F$ and Smooth Muscle Cell Proliferation}

Based on the fact that pigs with vWD also presented with decreased progression of atherosclerosis, Qin et al. [42] speculated that elevated expression of endothelial vWF may have mitogenic effects on smooth muscle cell proliferation. Using an in vitro model system, they found that mouse smooth muscle cell proliferation correlates positively with the concentration of vWF. Further studies in an in vivo system of carotid artery ligation revealed that intimal hyperplasia in carotid arteries was absent in low plasma vWF mice, and that treatment with the synthetic vasopressin desmopressin (DDAVP) moderately rescued plasma vWF levels. These results indicate that expression of vWF is capable of modulating, at least partially, intimal hyperplasia. 


\section{vWF and Tumor Cell Metastasis}

Platelets are important components of the hemostatic process, which is believed to support metastasis. When the platelet amount is reduced, metastasis is reduced as well. Recent studies have indicated that vWF, in particular, can function as a promoter of tumor cell metastasis $[43,44]$. For example, the B16-BL6 melanoma cell transplantable tumor cell line has been demonstrated to adhere to vWF through the membrane-expressed integrin $\alpha \mathrm{V} \beta 3$. In addition, vWF has been shown to promote adhesion of tumor cells through the Arg-Gly-Asp (RGD) sequence in its $\mathrm{C} 1$ domain. Finally, using an experimental pulmonary metastasis model system based on B16-BL6 melanoma cell or Lewis lung carcinoma cell transplantation into wild-type and vWF-deficient mice, vWF deficiency was shown to result in a significantly increased number of metastatic foci, but not increased tumor growth [45].

\section{New Roles for $v$ WF with Immune Cells}

Currently, many researchers have begun to investigate potential roles of vWF and the immune response. In particular, a novel role for vWF as a mediator of crosstalk between immune cells has been proposed.

\section{Leukocytes}

Leukocyte extravasation is an important inflammatory process that involves chemoattraction to the site of immune response to injury or infection, rolling adhesion as the leukocytes approach the site and begin to merge out of the blood flow, tight adhesion to the vessel wall at the site, and endothelial transmigration through the vessel wall to the site of action. Petri et al. [2] reported that vWF promotes leukocyte extravasation in a platelet- and GPIb-dependent manner, providing evidence that vWF may functionally contribute to inflammation.

\section{Neutrophils}

Neutrophil extracellular traps (NETs) are made within the vasculature by activated neutrophils. The NETs, themselves, are composed of DNA fibers, histones and antimicrobial proteins, which are catapulted out of the neutrophil into the pathogen-containing extracellular space. NETs have been shown to prevent the spread of a bacterial infection not only by physically entrapping the bacteria but by killing them by proteolytic degradation [46]. In the vasculature, NETs also provide a scaffold for platelets and subsequent thrombus formation [47]. Immunocytochemistry has revealed that vWF, fibronectin and fibrinogen are capable of binding to the NETs, thereby promoting platelet binding to NETs.

\section{Macrophages}

Macrophages play a key role in rapid immune clearance of infectious agents and tumor cells. A role for vWF in the mechanism of macrophage-based immune clearance was suggested by a study of spleen and liver tissues from vWF-deficient mice treated with recombinant $v W F$ or recombinant factor VIII. Immunohistochemical staining with the anti-mouse macrophage marker F4/80 indicated that vWF was enriched in macrophages using the anti-mouse macrophage marker F4/80 [12]. Of note, when macrophages were reduced in these mice by gadolinium chloride $(\mathrm{GdCl} 3)$ treatment, vWF clearance was promoted and vWF half-life was nearly doubled. Thus, it was hypothesized that macrophages are involved in the vWF clearance process.

\section{Dendritic Cells}

Dendritic cells (DCs) are critical immune modulators as they trigger the activation and proliferation of $\mathrm{T}$ cells. By incubating DCs derived from monocytes of healthy blood donors with a panel of bioactive molecules, Dasgupta et al. [3] found that DC-mediated endocytosis of factor VIII can be downregulated by vWF.

\section{Megakaryocytes}

Megakaryocytes are the precursors of platelets in mammalian bone marrow. Nurden et al. [48] performed a cohort study of both megakaryocytes and platelets from patients with von Willebrand type 2B disease and concluded that vWF could impair megakaryocytopoiesis.

\section{The Significance of vWF in Diseases}

The concentration of normal plasma vWF ranges from 5 to $15 \mu \mathrm{g} / \mathrm{ml}$. Defects in vWF secretion, assembly of vWF multimers, or overt proteolytic degradation can result in a low concentration of vWF, which manifests as vWD. On the contrary, impaired vWF degradation of ULvWF is a strong risk factor for TTP. Apart from these two diseases, vWF levels have been regarded as a thrombosis risk. Ongoing research efforts are aimed at gaining a better understanding of how vWF is regulated in disease conditions, particularly vascular-related diseases, and to determine its potential as a biomarker.

$v W F$ and $v W D$

vWD is the most common inherited human bleeding disorder and results from defects in plasma vWF quantity and/or quality [49]. According to phenotype analysis, 
Table 2. Therapeutic strategies for vWD

\begin{tabular}{lll}
\hline Drug & vWD type & Disadvantage \\
\hline $\begin{array}{ll}\text { Desmopressin/DDAVP } \\
\text { Fresh frozen plasma }\end{array}$ & type 1 & limited to type 1 \\
$\begin{array}{l}\text { Cryoprecipitate } \\
\text { vWF/factor VIII concentrates }\end{array}$ & $\begin{array}{l}\text { almost all types } \\
\text { type 3, type 2B and desmopressin-resistant }\end{array}$ & $\begin{array}{l}\text { pathogen transmission risk } \\
\text { expensive }\end{array}$ \\
\hline
\end{tabular}

Fresh frozen plasma and cryoprecipitate are still in use in developing countries.

vWD can be classified among six independent types: type 1 , types $2 \mathrm{~A}, 2 \mathrm{~B}, 2 \mathrm{M}$ and $2 \mathrm{~N}$, and type 3 [50]. Type $1 \mathrm{vWD}$ is characterized by a reduction both in the amount and activity of vWF. Type $2 \mathrm{vWD}$ is characterized by abnormal adhesion activity and functional tests will show an abnormality. Type $3 \mathrm{vWD}$ patients present with vWF levels that are nearly or absolutely undetectable. vWD is characterized by excessive mucocutaneous bleeding, which manifests clinically as epistaxis, menorrhagia, easy bruising and nose or oral cavity bleeding. Generally speaking, only a small portion of vWD cases are severe, and most of the vWD patients do not require extensive therapeutic intervention to stop the bleeding. Different therapeutic strategies are needed to treat patients according to the clinical classification of their vWD (table 2).

\section{$v W F$ and Thrombotic Thrombocytopenic Purpura}

Several clinical forms of TTP are currently recognized, including the acute single-episode TTP, familial TTP and relapsing TTP [51]. Up to half of TTP patients have been shown to have a higher vWF multimer size, as compared to that of healthy, non-TTP individuals. Several researches have reported that the normal vWF-cleaving protease activity is completely absent in patients with TTP [52-54]. Since platelet thrombi formation depends on the amount of platelets adhering to ULvWF, plasma ADAMTS13-targeted cleavage of ULvWF is key to maintaining a balance between coagulation and hemostasis. In TTP, ADAMTS13 fails to control thrombus growth, allowing the thrombus to grow continually and eventually leading to vessel occlusion. Absent or severely reduced quantity or activity of ADAMTS13 always causes patients to fail to timely degrade ULvWF multimers secreted by endothelial cells. The ULvWF multimeric strings remain bound to endothelial cells and cause deposition of platelet-rich thrombi. In addition, fluid shear stresses and the torque formed by ULvWF-platelet adherence may also promote the detachment of ULvWF [55].
Gene mutation of ADAMTS13 and autoimmune inhibitors targeting ADAMTS13 may further promote vWF aggregation and microvascular thrombosis [56]. In fact, ADAMTS13 gene mutations have been show to affect both the function and processing of ADAMTS13, resulting in vWF binding or cleavage inhibition [57].

\section{$v W F$ in Acquired von Willebrand Syndrome}

Acquired von Willebrand syndrome (AvWS) is a rare hemorrhagic disorder with multiple etiologies, including but not limited to myeloproliferative disorders, lymphoproliferative disorders, immune-mediated diseases, cardiovascular disorders, hypothyroidism, malignancies and altered shear stress $[58,59]$. While many mechanisms have been proposed for this disease, such as selective absorption of ULvWF multimers, nonselective absorption of vWF, shear-induced destruction of vWF, and increased proteolysis [59], the true molecular pathogenesis remains unknown. The type 1 AvWS is characterized by hypothyroidism and requires DDAVP therapy [60]. Most AvWS types mimic vWD type 1 or type $2 \mathrm{~A}$. Only two of the AvWS cases reported in the worldwide medical literature to date have mimicked vWD type $2 \mathrm{~B}[61,62]$. Still other types of AvWS have been reported, although they appear to be exceedingly rare. As medical research and global communication continue to advance, it is likely that more cases of AvWS will be recognized and reported to the international community.

\section{vWF as a Potential Clinical Biomarker}

Endothelial cells release a multitude of procoagulation and anticoagulation proteins that regulate the fine balance between hemostasis and thrombosis. The three major hemostatic regulatory molecules are vWF, thrombomodulin and tissue factor pathway inhibitor [63]. Plasma levels of the first two are increased significantly upon endothelial membrane injury, making them promising biomarkers of endothelial dysfunction $[64,65]$. 
Table 3. Recent studies evaluating vWF as a biomarker for vascular disorders

\begin{tabular}{|c|c|c|c|c|}
\hline Disease & Plasma/active $\mathrm{vWF}^{1}$ & Potential as a biomarker & $\mathrm{p}$ value & Reference \\
\hline $\mathrm{CHD}$ & 3.04 & yes, a risk factor for CHD & 0.01 & {$[63]$} \\
\hline $\begin{array}{l}\text { Cerebral sinus and venous } \\
\text { thrombosis }\end{array}$ & 1.52 & $\begin{array}{l}\text { yes, its role as a risk factor may be } \\
\text { mediated by factor VIII }\end{array}$ & 0.01 & {$[66]$} \\
\hline SLE related CVD & 1.4 & yes, a predictor of first CVD & 0.01 & {$[67]$} \\
\hline Ischemia stroke & 3.2 & $\begin{array}{l}\text { yes, associated with the occurrence of } \\
\text { acute ischemic stroke }\end{array}$ & $<0.01$ & {$[68]$} \\
\hline $\begin{array}{l}\text { Cirrhosis and portal } \\
\text { hypertension }\end{array}$ & 2.13 & $\begin{array}{l}\text { yes, correlates with liver function and } \\
\text { hepatic venous pressure gradient }\end{array}$ & $<0.001$ & {$[69]$} \\
\hline Atrial fibrillation & 4.47 & yes & $<0.001$ & {$[70]$} \\
\hline Hypertension & 1.21 & $\begin{array}{l}\text { yes, may help to identify patients with } \\
\text { essential HBP }\end{array}$ & $<0.001$ & {$[71]$} \\
\hline Sickle cell disease & ULvWF: $1.2-3.6$ & yes, correlates with the rate of hemolysis & $<0.01$ & {$[72]$} \\
\hline Obesity & $\begin{array}{l}\text { to normal: } 1.06 \\
\text { after gastric banding: } 0.83\end{array}$ & $\begin{array}{l}\text { yes, weight loss may reduce thrombotic } \\
\text { risk }\end{array}$ & $\begin{array}{l}0.004 \\
0.001\end{array}$ & {$[73]$} \\
\hline Hypertrophic cardiomyopathy & various & no & not given & {$[74]$} \\
\hline Alzheimer's disease & 1.04 & no & 0.74 & {$[65]$} \\
\hline$\overline{\mathrm{CM}}-\mathrm{R}$ & AUROC: 0.58 & no, but ppvWF can & 0.305 & {$[75]$} \\
\hline
\end{tabular}

AUROC = Area under the receiver operating characteristic curve; CHD = coronary heart disease; CM-R = retinopathy-validated cerebral malaria; $\mathrm{CVD}=$ cardiovascular disease; $\mathrm{HBP}=$ high blood pressure; $\mathrm{SLE}=$ systemic lupus erythematosus; $\mathrm{ppvWF}=$ pre-provWF.

${ }^{1}$ Fold-change, relative to control.

Many clinical case-cohort studies have set forth to evaluate the relationship between the onset and extent of endothelial cell-related diseases and vWF plasma levels (summarized in table 3). Some of the clinical trials and follow-up studies have successfully demonstrated that elevated plasma vWF is a risk factor of coronary heart disease [63], cerebral sinus and venous thrombosis [66], systemic lupus erythematosus [67], ischemia stroke [68], liver cirrhosis [69], atrial fibrillation [70], hypertension [71], sickle cell disease [72] and obesity [73]. On the other hand, several other studies have failed to establish an association between vWF and endothelium-related diseases, including hypertrophic cardiomyopathy [74], Alzheimer's disease [65] and retinopathy-validated cerebral malaria [75].

While some prospective studies have demonstrated that elevated vWF levels are associated with the severity of vascular disorders, the underlying mechanisms have yet to be determined. It also remains unclear whether vWF levels could act as an accurate marker of severity of endothelial damage. Plasma vWF levels are known to be influenced by many of the established cardiovascular risk factors, such as age, cholesterol and hypertension [76], and any of these may complicate the use of vWF as a diagnostic or prognostic biomarker in clinical practice.

\section{$v W F$ and Liver Diseases}

The liver is one of the primary organs that produce clotting factors, anticoagulant proteins and fibrinolytic factors. Patients with liver dysfunction tend to suffer from bleeding or thrombi disorders that stem from hemostatic disturbances. Recent studies have shown that vWF is involved in the development and progression of liver diseases such as liver cirrhosis, alcoholic hepatitis and liver transplantation-related disorders.

Plasma levels of vWF antigen (vWF:Ag) are significantly higher in patients with liver cirrhosis than in healthy controls $[69,77]$. Lisman et al. [77] reported that a substantial elevation of vWF:Ag accompanied aggravation of cirrhosis, according to Child-Pugh classification scores (A: 380\%; B:500\%; C: 760\%). In addition, vWF:RCo (von Willebrand factor ristocetin cofactor) levels have also been shown to increase in conjunction with vWF:Ag. However, the overall ratio of vWF:RCo/vWF:Ag is lower in cirrhotic patients than in healthy controls, indicating an impairment in the functional capacity of the liver. Interestingly, La Mura et al. [69] reported that a positive linear correlation exists between levels of vWF and the hepatic venous pressure gradient, but also found that the prognostic value of vWF was not associated with the gra- 
dient. These results suggest that a higher vWF level correlates to poorer outcome in hepatic cirrhosis, but more studies are necessary to confirm this.

\section{$v W F$ and Tumors}

vWF abnormality has been reported in both hematologic malignancies and nonhematologic malignancies, including chronic lymphocytic leukemia [78], acute lymphoblastic leukemia [79], colorectal carcinoma [80], leiomyosarcoma [81], breast cancer [82] and prostate cancer [83]. In an experimental metastasis mouse model, vWF was observed to inhibit tumor metastasis [45]. In fact, several clinical trials have shown significantly elevated levels of plasma vWF in various cancer patients [84-86]. It is reported that during the process of tumor angiogenesis, platelets produce VEGF $[87,88]$, which subsequently promotes endothelial proliferation and elevated plasma levels of vWF. One study of tumor angiogenesis determined that vWF staining represented an effective maker of microvessel density [89], which itself may be a prognostic marker for cancer progression or patient survival. Another study of colorectal cancer patients indicated that large numbers of vWF-positive microvessels in the presence of tumor- associated macrophages can be an indicator of poor prognosis [90]. Future studies of the molecular mechanisms underlying tumor angiogenesis and metastasis are expected to provide further insights into the tumor-related roles of vWF.

\section{Concluding Remarks}

A substantial amount of data has emerged over the past decades to suggest myriad roles of vWF in a broad range of vascular- and immune-related normal processes and disease, but many questions remain. For example, does vWF's involvement in angiogenesis and metastasis indicate a consequential (and therapeutically manipulatable) correlation with tumorigenesis or tumor progression? Is the association between vWF and cardiovascular disease robust enough for vWF to be used as an accurate and specific biomarker? Until the precise molecular mechanisms of vWF in each disease's pathogenesis are elucidated, the answers to these questions would be clear. Regardless, the body of vWF data to date has uncovered many new and clinically-promising functions of vWF beyond its original documented action as a mediator of hemostasis.

\section{Acknowledgements}

We would like to thank Dr. Jennifer C. van Velkinburgh (van Velkinburgh Initiative for Collaboratory BioMedical Research, Santa Fe, N. Mex., USA) for helpful discussions and for polishing the manuscript.

\section{References}

1 De Meyer SF, Deckmyn H, Vanhoorelbeke K: von Willebrand factor to the rescue. Blood 2009;113:5049-5057.

-2 Petri B, Broermann A, Li H, Khandoga AG, Zarbock A, Krombach F: von Willebrand factor promotes leukocyte extravasation. Blood 2010;116:4712-4719.

-3 Dasgupta S, Repesse Y, Bayry J, Navarrete AM, Wootla B, Delignat S, Irinopoulou T, Kamaté C, Saint-Remy JM, Jacquemin M, Lenting PJ, Borel-Derlon A, Kaveri SV, Lacroix-Desmazes S: vWF protects FVIII from endocytosis by dendritic cells and subsequent presentation to immune effectors. Blood 2007;109:610-612.

-4 Ginsburg D, Handin RI, Bonthron DT, Donlon TA, Bruns GA, Latt SA, Orkin SH: Human von Willebrand factor (vWF): isolation of complementary DNA (cDNA) clones and chromosomal localization. Science 1985; 228:1401-1406.

-5 Allen S, Abuzenadah AM, Hinks J, Blagg JL, Gursel T, Ingerslev J, Goodeve AC, Peake IR,
Daly ME: A novel von Willebrand diseasecausing mutation (Arg273Trp) in the von Willebrand factor propeptide that results in defective multimerization and secretion. Blood 2000;96:560-568.

6 Wagner DD, Marder VJ: Biosynthesis of von Willebrand protein by human endothelial cells: processing steps and their intracellular localization. J Cell Biol 1984;99:2123-2130.

-7 Titani K, Kumar S, Takio K, Ericsson LH, Wade RD, Ashida K, Walsh KA, Chopek MW, Sadler JE, Fujikawa K: Amino acid sequence of human von Willebrand factor. Biochemistry 1986;25:3171-3184.

8 Wang JW, Valentijn KM, de Boer HC, Dirven RJ, van Zonneveld AJ, Koster AJ, Voorberg J, Reitsma PH, Eikenboom J: Intracellular storage and regulated secretion of von Willebrand factor in quantitative von Willebrand disease. J Biol Chem 2011;286:24180-24188.

-9 Zarei S, Frieden M, Rubi B, Villemin P, Gauthier BR, Maechler P, Vischer UM: Dopamine modulates von Willebrand factor secretion in endothelial cells via D2-D4 receptors. J Thromb Haemost 2006;4:15881595.

10 Lenting PJ, Pegon JN, Groot E, de Groot PG: Regulation of von Willebrand factor- platelet interactions. Thromb Haemost 2010;104: 449-455.

- 11 Lenting PJ, Westein E, Terraube V, Ribba AS, Huizinga EG, Meyer D, de Groot PG, Denis CV: An experimental model to study the in vivo survival of von Willebrand factor: basic aspects and application to the $\mathrm{R} 1205 \mathrm{H}$ mutation. J Biol Chem 2004;279:12102-12109.

12 van Schooten CJ, Shahbazi S, Groot E, Oortwijn BD, Marijke Van den B, Ceclie VD, Lenting PJ: Macrophages contribute to the cellular uptake of von Willebrand factor and factor VIII in vivo. Blood 2005;112:17041712 .

13 Crawley JT, Groot RD, Xiang Y, Luken BM, Lane DA: Unravelling the scissile bond: how ADAMTS13 recognises and cleaves von Willebrand factor. Blood 2011;118:3212-3221. 
14 Arya M, Anvari B, Romo GM, Cruz MA, Dong JF, McIntire LV, Moake JL, Lopez JA: Ultralarge multimers of von Willebrand factor form spontaneous high-strength bonds with the platelet glycoprotein Ib-IX complex: studies using optical tweezers. Blood 2002; 99:3971-3977.

-15 Furlan M, Robles R, Lämmle B: Partial purification and characterization of a protease from human plasma cleaving von Willebrand factor to fragments produced by in vivo proteolysis. Blood 1996;87:4223-4234.

16 Rens de G, David AL, Crawley JTB: The ADAMTS13 metalloprotease domain roles of subsites in enzyme activity and specificity. Blood 2010;116:3064-3072.

-17 Zanardelli S, Chion AC, Groot E, Lenting PJ, Mckinnon TA, Laffan MA, Tseng M, Lane DA: A novel binding site for ADAMTS13 constitutively exposed on the surface of globular vWF. Blood 2009;114:2819-2828.

18 Luken BM, Winn LYN, Emsley J, Lane DA, Crawley JTB: The importance of vicinal cysteines, C1669 and C1670, for von Willebrand factor A2 domain function. Blood 2010;115: 4910-4913.

-19 Raife TJ, Cao W, Atkinson BS, Bedell B, Montgomery RR, Lentz SR, Johnson GF, Zheng XL: Leukocyte proteases cleave von Willebrand factor at or near the ADAMTS13 cleavage site. Blood 2009;114:1666-1674.

-20 Tao Z, Wang Y, Choi H, Bernardo A, Nishio K, Sadler JE, López JA, Dong JF: Cleavage of ultralarge multimers of von Willebrand factor by C-terminal-truncated mutants of ADAMTS-13 under flow. Blood 2005;106: 141-143.

-21 Wang A, Liu F, Dong N, Ma Z, Zhang J, Su J, Zhao Y, Ruan C: Thrombospondin-1 and ADAMTS13 competitively bind to vWF A2 and A3 domains in vitro. Thromb Res 2010; 126:260-265.

-22 Pimanda JE, Ganderton T, Maekawa A, Yap CL, Lawler J, Kershaw G, Chesterman CN, Hogg PJ: Role of thrombospondin-1 in control of von Willebrand Factor multimer size in mice. J Biol Chem 2004;279:21439-21448.

$\checkmark 23$ Bonnefoy A, Daenens K, Feys HB, Vos RD, Vandervoort P, Vermylen J, Lawler J, Hoylaerts MF: Thrombospondin-1 controls vascular platelet recruitment and thrombus adherence in mice by protecting (sub)endothelial vWF from cleavage by ADAMTS13. Blood 2006;107:955-964.

24 Siedlecki CA, Lestini BJ, Kottke-Marchant KK, Eppell SJ, Wilson DL, Marchant RE: Shear-dependent changes in the three-dimensional structure of human von Willebrand factor. Blood 1996;88:2939-2950.

-25 Shankaran H, Alexandridis P, Neelamegham $\mathrm{S}$ : Aspects of hydrodynamic shear regulating shear-induced platelet activation and selfassociation of von Willebrand factor in suspension. Blood 2003;101:2637-2645.
6 Dong JF: Cleavage of ultra-large von Willebrand factor by ADAMTS-13 under flow conditions. J Thromb Haemost 2005;3:1710-1716.

27 Zhang XH, Halvorsen K, Zhang CZ, Wong WP, Springer TA: Mechanoenzymatic cleavage of the ultralarge vascular protein von Willebrand factor. Science 2009;324:1330 1334.

28 Andrews RK, Berndt MC: Platelet physiology and thrombosis. Thromb Res 2004;114: 447-453.

29 Hoffmeister KM, Felbinger TW, Falet H, Denis CV, Bergmeier W, Mayadas TN, von Andrian UH, Wagner DD, Stossel TP, Hartwig JH: The clearance mechanism of chilled blood platelets. Cell 2003;112:87-97.

30 Cheng H, Yan R, Li S, Yuan Y, Liu J, Ruan C, Dai K: Shear-induced interaction of platelets with von Willebrand factor results in glycoprotein Ib $\alpha$ shedding. Am J Physiol Heart Circ Physiol 2009;297:2128-2135.

31 Mody NA, Lomakin O, Doggett TA, Diacovo TG, King MR: Mechanics of transient platelet adhesion to von Willebrand factor under flow. Biophys J 2005;88:1432-1443.

32 Huang J, Roth R, Heuser JE, Sadler JE: Integrin alpha(v)beta(3) on human endothelial cells binds von Willebrand factor strings under fluid shear stress. Blood 2009;113:15891597.

33 Fuchs B, Budde U, Schulz A, Kessler CM, Fisseau C, Kannicht C: Flow-based measurements of von Willebrand factor (vWF) function: binding to collagen and platelet adhesion under physiological shear rate. Thromb Res 2010;125:239-245.

34 Bonnefoy A, Romijn RA, Vandervoort PAH, Van Rompaey I, Vermylen J, Hoylaerts MF: von Willebrand factor A1 domain can adequately substitute for $\mathrm{A} 3$ domain in recruitment of flowing platelets to collagen. J Thromb Haemost 2006;4:2151-2161.

35 Ridddell AF, Gomez K, Millar CM, Mellars G, Gill S, Brown SA, Sutherland M, Laffan MA, Mckinnon TA: Characterization of W1745C and S1783A: 2 novel mutations causing defective collagen binding in the A3 domain of von Willebrand factor. Blood 2009;114:3489-3496.

36 Romijn RA, Westein E, Bouma B, Schiphorst ME, Sixma JJ, Lenting PJ, Huizinga EG: Mapping the collagen-binding site in the von Willebrand Factor A3-domain. J Biol Chem 2003;278:15035-15039.

37 Bovenschen N, Mertens K, Hu L, Havekes L, van Vlijmen B: LDL receptor cooperates with LDL receptor-related protein in regulating plasma levels of coagulation factor VIII in vivo. Blood 2005;106:906-912.

38 Fressinaud E, Meyer D: International survey of patients with von Willebrand disease and angiodysplasia. Thromb Haemost 1993;70: 546.
39 Junquera F, Saperas E, de Torres I, Vidal MT, Malagelada JR: Increased expression of angiogenic factors in human colonic angiodysplasia. Am J Gastroenterol 1999;94:10701076.

40 Starke RD, Ferraro F, Paschalaki KE, Dryden NH, McKinnon TAJ, Sutton PE, Payne EM, Haskard DO: Endothelial von Willebrand factor regulates angiogenesis. Blood 2011; 117:1071-1080.

-41 Tigges U, Hyer EG, Scharf J, Stallcup WB: FGF2-dependent neovascularization of subcutaneous Matrigel plugs is initiated by bone marrow-derived pericytes and macrophages. Development 2008;135:523-532.

-42 Qin F, Impeduglia T, Schaffer P, Dardik H: Over-expression of von Willebrand factor is an independent risk factor for pathogenesis of intimal hyperplasia: preliminary studies. J Vasc Surg 2003;37:433-439.

$\checkmark 43$ Terraube V, Pendu R, Baruch D, Gebbink MF, Meyer D, Lenting PJ, Denis CV: Increased metastatic potential of tumor cells in von Willebrand factor-deficient mice. J Thromb Haemost 2006;4:519-526.

44 Terraube V, Marx I, Denis CV: Role of von Willebrand factor in tumor metastasis. Thromb Res 2007;120(suppl 2):S64-S70.

45 Terraube V, Pendu R, Baruch D, Gebbink MF, Meyer D, Lenting PJ, Denis CV: Increased metastatic potential of tumor cells in von Willebrand factor-deficient mice. J Thromb Haemost 2006;4:519-526.

46 Brinkmann V, Reichard U, Goosmann C, Fauler B, Weiss DS, Weinrauch Y, Zychlinsky A: Neutrophil extracellular traps kill bacteria. Science 2004;303:1532-1535.

47 Fuchs TA, Brill A, Duerschmied D, Schatzberg D, Monestier M, Myers DD Jr, Wrobleski SK, Wakefield TW, Hartwig JH, Wagner DD: Extracellular DNA traps promote thrombosis. Proc Natl Acad Sci USA 2010; 107:15880-15885.

48 Nurden P, Gobbi G, Nurden A, Enouf J, Youlyouz-Marfak I, Carubbi C, La Marca S, Punzo M, Baronciani L, De Marco L, Vitale M, Federici AB: Abnormal vWF modifies megakaryocytopoiesis: studies of platelets and megakaryocyte cultures from patients with von Willebrand disease type 2B. Blood 2010; 115:2649-2656.

49 Trossaert M, Ternisien C, Lefrancois A, Llopis L, Goudemand J, Sigaud M, Fouassier M, Caron C: Evaluation of an automated von Willebrand factor activity assay in von Willebrand disease. Clin Appl Thromb Hemost 2011;17:E25-E29.

50 Michiels JJ, van Vliet HH, Berneman Z, Schroyens W, Gadisseur A: Managing patients with von Willebrand disease type 1,2 and 3 with desmopressin and von Willebrand factor-factor VIII concentrate in surgical settings. Acta Haematol 2009;121:167176. 
-51 Moore JC, Hayward CP, Warkentin TE, Kelton JG: Decreased von Willebrand factor protease activity associated with thrombocytopenic disorders. Blood 2001;98:18421846.

52 Moake J, Rudy C, Troll J, Weinstein M, Colannino N, Azocar J, Seder R, Hong S, Deykin D: Unusually large plasma factor VIII: von Willebrand factor multimers in chronic relapsing thrombotic thrombocytopenic purpura. N Engl J Med 1982;307:1432-1435.

53 Furlan M, Robles R, Solenthaler M, Wassmer M, Sandoz P, Lammie B: Deficient activity of von Willebrand factor-cleaving protease in chronic relapsing thrombotic thrombocytopenic purpura. Blood 1997;89:3097-3103.

54 Moake JL: Thrombotic microangiopathies. N Engl J Med 2002;347:589-600.

-55 Dong JF, Moake JL, Nolasco L: ADAMTS-13 rapidly cleaves newly secreted ultralarge von Willebrand factor multimers on the endothelial surface under flowing conditions. Blood 2002;100:4033-4039.

56 Levy VG, Nichols WC, Lian EC, Foroud T, McClintick JN, McGee BM, Yang AY, Siemienia DR, Stark KR, Gruppok R, Sarode R, Shurin SB, Chandrasekaran V: Mutations in a member of the ADAMTS gene family cause thrombotic thrombocytopenic purpura. $\mathrm{Na}$ ture 2001;413:488-494.

57 Caprioli J, Castelletti F, Bucchioni S: Complement factor $\mathrm{H}$ mutations and gene polymorphisms in haemolytic uraemic syndromethe C-257T the A2089G and the G2881T polymorphisms are strongly associated with the disease. Hum Mol Genet 2003;12:33853395.

-58 Shetty S, Kasatkar P, Ghosh K: Pathophysiology of acquired von Willebrand disease: a concise review. Eur J Haematol 2011;87:99106.

59 Leimkuhler K, Bach F, Kuhlmann S, Feidicker B, Heim MU, Susemihl C, Schmidt B, Mertzlufft F: Acquired von Willebrand's disease type $2 \mathrm{~A}$ following arteriovenous fistula for haemodialysis? (in German) Hämostaseologie 2011;31:118-122.

-60 Michiels JJ, Schroyens W, Berneman Z, van der Planken M: Acquired von Willebrand syndrome type 1 in hypothyroidism: reversal after treatment with thyroxine. Clin Appl Thromb Hemost 2001;7:113-115.

-61 Drouin J, Lillicrap DP, Izaguirre CA, Sutherland M, Windsor S, Benford K, Hoogendorn $\mathrm{H}$, Giles AR: Absence of a bleeding tendency in severe acquired von Willebrand's disease: the role of platelet von Willebrand factor in maintaining normal hemostasis. Am J Clin Pathol 1989;92:471-478.

-62 Karger R, Weippert-Kretschmer M, Budde $\mathrm{U}$, Kretschmer V: Diagnosis and therapeutic management in a patient with type $2 \mathrm{~B}$-like acquired von Willebrand syndrome. Blood Coagul Fibrinolysis 2011;22:144-147.
63 Morange PE, Simon C, Alessi MC, Luc G, Arveiler D, Ferrieres J, Amouyel P, Evans A, Ducimetiere P, Juhan-Vague I: Endothelial cell markers and the risk of coronary heart disease: the prospective epidemiological study of myocardial infarction (PRIME) study. Circulation 2004;109:1343-1348.

64 Blann AD, McCollum CN, Lip GY: Relationship between plasma markers of endothelial cell integrity and the Framingham cardiovascular disease risk-factor scores in apparently healthy individuals. Blood Coagul Fibrinolysis 2002;13:513-518.

65 Yavuz BB, Dede DS, Yavuz B, Cankurtaran M, Halil M, Ulger Z, Cankurtaran ES, Aytemir K, Kabakci G, Haznedaroglu IC, Ariogul S: Potential biomakers for vascular damage in Alzheimer's disease: thrombomodulin and von Willebrand factor. J Nutr Health Aging 2010;14:439-441.

66 Bugnicourt JM, Roussel B, Tramier B, Lamy C, Godefroy O: Cerebral venous thrombosis and plasma concentrations of factor VIII and von Willebrand factor: a case control study. J Neurol Neurosurg Phychiatry 2007;78: 699-701.

67 Gustafsson J, Gunnarsson I, Börjesson O, Pettersson S, Möller S, Fei GZ, Elvin K, Simard JF, Hansson LO, Lundberg IE, Larsson A, Svenungsson E: Predictors of the first cardiovascular event in patients with systemic lupus erythematosus - a prospective cohort study. Arthritis Res Ther 2009;11:186-196.

68 Bongers TN, de Maat MP, van Goor ML, Bhagwanbali V, van Vliet $\mathrm{HH}$, Gómez García EB, Dippel DW, Leebeek FW: High von Willebrand factor levels increase the risk of first ischemic stroke: influence of ADAMTS13, inflammation, and genetic variability. Stroke 2006;37:2672-2677.

-69 La Mura V, Reverter JC, Flores-Arroyo A, Raffa S, Reverter E, Seijo S, Abraldes JG, Bosch J, Garcia-Pagan JC: Von Willebrand factor levels predict clinical outcome in patients with cirrhosis and portal hypertension. Gut 2011;60:1133-1138.

70 Roldán V, Marín F, Muiña B, Torregrosa JM, Hernández-Romero D, Valdés M, Vicente V, Lip GY: Plasma von Willebrand factor levels are an independent risk factor for adverse events including mortality and major bleeding in anticoagulated atrial fibrillation patients. J Am Coll Cardiol 2011;57:2496-2504.

71 Khaleghi M, Singletary L, Kondragunta V, Bailey KR, Turner ST, Mosley TH Jr, Kullo IJ: Haemostatic markers are associated with measures of vascular disease in adults with hypertension. J Hum Hypertens 2009;23: 530-537.

72 Chen J, Hobbs WE, Le J, Lenting PJ, de Groot PG, López JA: The rate of hemolysis in sickle cell disease correlates with the quantity of active von Willebrand factor in the plasma. Blood 2011;117:3680-3683.
Cugno M, Castelli R, Mari D, Mozzi E, Zappa MA, Boscolo-Anzoletti M, Roviaro G, Mannucci PM: Inflammatory and prothrombotic parameters in normotensive non-diabetic obese women: effect of weight loss obtained by gastric banding. Intern Emerg Med 2012; 7:237-242.

74 Francisco C, Juan AV, Antonio GH, Francisco RE: Plasma levels of von Willebrand factor are increased in patients with hypertrophic cardiomyopathy. Thromb Res 2010;126:4650.

-75 Conroy AL, Phiri H, Hawkes M, Glover S, Mallewa M, Seydel KB, Taylor TE, Molyneux ME, Kain KC: Endothelium-based biomarkers are associated with cerebral malaria in Malawian children: a retrospective casecontrol study. PLoS ONE 2010;5:e15291.

76 Spiel AO, Gilbert JC, Jilma B: von Willebrand factor in cardiovascular disease: focus on acute coronary syndromes. Circulation 2008;117:1449-1459.

77 Lisman T, Bongers TN, Adelmeijer J, Janssen HL, de Maat MP, de Groot PG, Leebeek FW: Elevated levels of von Willebrand factor in cirrhosis support platelet adhesion despite reduced functional capacity. Hepatology 2006; 44:53-61.

78 Zetterberg E, Lundberg LG, Palmblad J: Characterization of blood vessels in bone marrow from patients with chronic myeloid leukemia and polycythemia vera. Scand J Clin Lab Invest 2004;64:641-647.

79 Hatzipantelis ES, Athanassiou-Metaxa M, Gombakis N, Tzimouli V, Taparkou A, SidiFragandrea V, Garipidou V, Papageorgiou T, Kleta D, Koliouskas DE, AthanasiadouPiperopoulou F: Thrombomodulin and von Willebrand factor: relation to endothelial dysfunction and disease outcome in children with acute lymphoblastic leukemia. Acta Haematol 2011;125:130-135.

80 Liu G, Ren YM: Effect of von Willebrand factor on the biological characteristics of colorectal cancer cells. Zhonghua Wei Chang Wai Ke Za Zhi 2010;13:616-619.

81 Kim SM, Myoung H, Choung PH, Kim MJ, Lee SK, Lee JH: Metastatic leiomyosarcoma in the oral cavity: case report with protein expression profiles. J Craniomaxillofac Surg 2009;37:454-460.

-82 Jiang WG, Watkins G, Douglas-Jones A, Holmgren L, Mansel RE: Angiomotin and angiomotin like proteins, their expression and correlation with angiogenesis and clinical outcome in human breast cancer. BMC Cancer 2006;6:16.

-83 Josefsson A, Wikstrom P, Granfors T, Egevad L, Karlberg L, Stattin P, Bergh A: Tumor size, vascular density and proliferation as prognostic markers in GS 6 and GS 7 prostate tumors in patients with long follow-up and non-curative treatment. Eur Urol 2005;48: 577-583. 
-84 Schellerer VS, Mueller-Bergh L, Merkel S, Zimmermann R, Weiss D, Schlabrakowski A, Naschberger E, Sturzl M, Hohenberger W, Croner RS: The clinical value of von Willebrand factor in colorectal carcinomas. Am J Transl Res 2011;3:445-453.

$>85$ Toth B, Nieuwland R, Liebhardt S, Ditsch N, Steinig K, Stieber P, Rank A, Gohring P, Thaler CJ, Friese K, Bauerfeind I: Circulating microparticles in breast cancer patients: a comparative analysis with established biomarkers. Anticancer Res 2008;28:1107-1112.
86 Martini F, Ferroni P, Guadagni F, Basili S, Spila A, D’Alessandro R, Mineo D, Laudisi A, Portarena I, Mariotti S, Ambrogi V, Mineo TC, Roselli M: Plasma von Willebrand factor antigen levels in non-small cell lung cancer patients. Anticancer Res 2005;25:403-407.

87 Caine GJ, Lip GY, Blann AD: Platelet-derived VEGF, Flt-1, angiopoietin-1 and P-selectin in breast and prostate cancer: further evidence for a role of platelets in tumour angiogenesis. Ann Med 2004;36:273-277.

88 Pinedo HM, Verheul HM, D’Amato RJ, Folkman J: Involvement of platelets in tumour angiogenesis? Lancet 1998;352:1775-1777.
89 Sinha S, Cao Y, Dutta S, Wang E, Mukhopadhyay D: VEGF neutralizing antibody increases the therapeutic efficacy of vinorelbine for renal cell carcinoma. J Cell Mol Med 2010;14:647-658.

-90 Lackner C, Jukic Z, Tsybrovskyy O, Jatzko G, Wette V, Hoefler G, Klimpfinger M, Denk H, Zatloukal K: Prognostic relevance of tumour-associated macrophages and von Willebrand factor-positive microvessels in colorectal cancer. Virchows Arch 2004;445: 160-167. 